\title{
Nurses Compassion Fatigue during the Pilgrim (Al-Hajj) Season
}

\author{
Usama S. Saleh ${ }^{a, b}$ Patricia Jenkins ${ }^{c}$ Bassem Saleh $^{d}$ Moath Saleh $^{e}$ \\ Hiba Abu Sammour ${ }^{f}$ Darwina Tiking ${ }^{f}$ Emad Abujoudeh ${ }^{g}$
}

aKing Abdullah Medical City, Makkah, Saudi Arabia; ${ }^{b}$ College of Nursing and Advanced Health Professions, The Chicago School of Professional Psychology, Richardson, TX, USA; 'Nursing Faculty, College of Nursing and Advanced Health Professions, The Chicago School of Professional Psychology, Richardson, TX, USA; dNursing

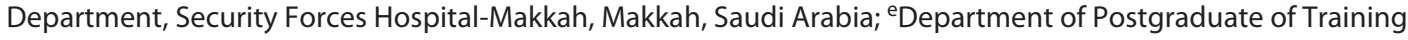
of Nursing and Allied Health, Nursing and Allied Health, King Abdullah Medical City, Makkah, Saudi Arabia; fDepartment of Postgraduate of Training of Nursing and Allied Health, King Abdullah Medical City, Makkah, Saudi Arabia; ${ }^{9}$ Department of Nursing, Security Forces Hospital-Makkah, Makkah, Saudi Arabia

\section{Keywords}

Compassion fatigue - Burnout - Secondary traumatic stress · Compassion satisfaction · Self-compassion · Nurses · Pilgrim (Al-Hajj) · Muslims · Mecca (Makkah) · Saudi Arabia

\begin{abstract}
Background: Compassion fatigue leads to behavioral, emotional, and physical changes, which affect the nurse, as well as the nurse-patient relationship. The consequences of compassion fatigue are not limited to the personal well-being of nurses but are also associated with poorer patient outcomes, increased thoughts of quitting among nurses, and higher job turnover rates. Objective: The purpose of this study was to examine the risk for compassion fatigue in nurses working a special assignment consisting of 15 consecutive 12-h days during the 1440 (2018) Al-Hajj pilgrimage season in Mecca (Makkah), Saudi Arabia. Methods: This study was a descriptive survey. A convenience sample of 542 nurses working a special nursing assignment during the Al-Hajj pilgrimage
\end{abstract}

karger@karger.com www.karger.com/sjh

Karger $\stackrel{\text { ' }}{5}$
(C) 2021 The Author(s)

Published by S. Karger AG, Basel

This article is licensed under the Creative Commons AttributionNonCommercial-NoDerivatives 4.0 International License (CC BYNC-ND) (http://www.karger.com/Services/OpenAccessLicense) Usage and distribution for commercial purposes as well as any distribution of modified material requires written permission. was recruited from 2 large metropolitan hospitals located in the center of Mecca. Three online surveys were completed (1) the Demographic Information Form, (2) the Professional Characteristics Information Form, and the (3) Professional Quality of Life Scale (ProQOL 5). Results: The sample yielded a moderate risk of compassion fatigue (Burnout [BO] $[M=$ $22.5, \mathrm{SD}=5.7]$, secondary traumatic stress $[M=25.0, \mathrm{SD}=$ $6.4])$, and compassion satisfaction (CS) $(M=40.5, S D=6.0)$. There was a positive relationship between the number of working days and compassion fatigue (BO $[r=0.16, N=542$, $p<0.01]$, secondary trauma stress $[r=0.90, N=542, p<$ $0.05])$, and a negative relationship with CS $(r=-0.20, N=542$, $p<0.01$ ). Level of competence (Novice-Expert) was associated with levels of CS (X2 $[4, N=540]=12.70, p=0.013)$ and with levels of BO (X2 $[4, N=540]=10.48, p=0.033)$. Conclusion: Hospitals need to provide a healthy, supportive, and positive workplace. Nurse managers must provide a compassionate leadership style. Nurses must practice self-compassion and ensure work-life balance.

(C) 2021 The Author(s)

Published by S. Karger AG, Basel 


\section{Nurses Compassion Fatigue during the Pilgrim (Al-Hajj) Season}

Mecca is the holy city and capital of Saudi Arabia, where Muslims come to worship with the annual Hajj pilgrimage, a homage to the last pilgrimage of the Prophet Muhammad. The pilgrimage is the world's largest yearly religious mass gathering and is a requirement for any nondisabled member of the Islamic faith, at least once in their lifetime. During the pilgrimage season, about 2.5 million Muslims from all over the world arrive in Mecca and stay from 10 to 30 days [1]. During the 15-day peak period, all health-care institutions, emergency services, air ambulances, disaster management centers, police departments, and other related services are placed on high alert to be able to intervene appropriately in case of any crowd emergencies [2]. During this period, nurses are recruited to work 12-h shifts for 15 consecutive days. Although there are financial rewards, nurses suffer from physical exhaustion and emotional frustration during this lengthy assignment, possibly leading to compassion fatigue. This study will focus on nurses who are working in the holiest place of Muslims, Mecca.

\section{Literature Review}

\section{Compassion Fatigue}

Compassion is considered the hallmark of caring in nursing $[3,4]$. Professional nursing care has a recognized obligation to care for patients holistically and compassionately, which includes addressing the physical, emotional, psychosocial, and spiritual components of care. While delivering care with compassion and kindness is an integral part of nursing care $[5,6]$, constant exposure to patients who are suffering or traumatized may diminish nurses' resources leading to compassion fatigue. The most commonly used definition of compassion fatigue was developed by Figley [7], who described it "a state of exhaustion and dysfunction biologically, psychologically, and socially as a result of prolonged exposure to compassion stress and all it invokes" (p. 253).

The true prevalence of compassion fatigue is difficult to determine and may range from 7 to $40 \%$ [8]. Sinclair et al. [9] found that $20-40 \%$ of nurses in the USA have reported experiencing compassion fatigue. In a recent report on the state of well-being among nurses, over 3,802 nurses were surveyed, and $47.47 \%$ reported a high level of distress, with over half of the nurses reporting job burn- out (BO), along with emotional problems (anxiety, depression, and irritability) [10].

Compassion fatigue is related to the concepts of $\mathrm{BO}$ and secondary traumatic stress. $\mathrm{BO}$ is characterized by emotional exhaustion, frustration, anger, and depression, and secondary traumatic stress results in negative feelings operated by fear and work-related trauma [11]. Fatigue due to secondary traumatic stress is evidenced by physical, emotional, social, and spiritual exhaustion, along with a loss of coping ability $[12,13]$.

Nurses with higher levels of compassion fatigue report disturbances in their personal relationships, a reduction in work productivity, and negative attitudes toward work [14]. The consequences of compassion fatigue are not limited to the personal well-being of nurses, as many studies have demonstrated that nurses' compassion fatigue can be detrimental to patient care. Alharbi and others (in press) [15] examined the relationship between compassion fatigue with nurse-sensitive indicators. They found that high levels of compassion fatigue may be reflected in communication issues, such as in handover reporting that would increase the rate-of nurse-sensitive indicators and level of compassion fatigue. Sun et al. [16] examined nursing work errors, job satisfaction, and job BO. They found a nursing error rate of $65.61 \%$ and that the occurrence of nursing work errors was related to job satisfaction and job BO. High levels of $\mathrm{BO}$ are associated with higher rates of patient mortality [17], and urinary tract and surgical site infections [14]. At the institutional level, compassion fatigue results in greater job turnover and increased thoughts of quitting among nurses $[18,19]$.

\section{Compassion Satisfaction}

In contrast to compassion fatigue, compassion satisfaction (CS) is the positive aspect of one's professional work life, capturing the pleasure derived from achieving and accomplishing work-related goals. Affirmative experiences, such as compassionately providing care with empathy, can enrich the life of the health-care provider [20]. $\mathrm{CS}$ is the reward of caregiving, experienced as a sense of pleasure or fulfillment is derived from one's work [21]. Generally, higher levels of CS are associated with lower levels of compassion fatigue [22].

\section{Study Purpose}

This study sought to evaluate the levels of compassion fatigue among nurses participating in the year of 1440 (2018) intensive pilgrim nursing assignment. The relationships between demographic and professional characteristics with levels of compassion fatigue were examined.
Saleh/Jenkins/Saleh/Saleh/Abu Sammour/ Tiking/Abujoudeh 
This study addressed the following research questions:

- What is the effect of working $12 \mathrm{~h}$ for 15 -consecutive working days on nurses' levels of compassion fatigue during the 1440 (2018) pilgrim (AL-Hajj) season?

- What are the relationships between nurses' demographic and professional characteristics with the levels of compassion fatigue?

\section{Methods}

A cross-sectional design and descriptive survey methodology were used to examine compassion fatigue and CS among nurses working a special nursing assignment during the Al-Hajj pilgrimage.

\section{Sample}

A convenience sample of nurses employed in 2 metropolitan hospitals in Mecca, located in the Western province of Saudi Arabia, was recruited. Nurses working the Mass Pilgrim Nursing Assignment during the Al-Hajj pilgrimage were eligible for sample recruitment. The work contract specified that the nurses agreed to work 15 consecutive days of 12 -h shifts. All nurses employed by the hospitals demonstrate English proficiency.

\section{Ethical Considerations}

Permission to conduct the study was granted by the Institutional Review Board of each hospital. An email announcement was sent to all nurses who met the inclusion criteria, informing them about the study and the expected start date. The purpose of this study was provided along with an explanation of confidentiality and data anonymity procedures. A personalized email message was then sent to all eligible subjects on day \# 5 of the Mass Pilgrim Nursing Assignment. The email message contained the following: (1) a description of the nature and purpose of the study, (2) a web link for their informed consent, (3) a web link to the study's surveys, and (4) the contact information of the researchers. The email described human subjects' rights and indicated that consent to participate would be determined by clicking on the informed consent link. Subjects needed to click on "agree" after reading the informed consent to be able to access the study's surveys.

\section{Data Collection Instruments}

The participants completed the 3 surveys via the web links provided in the email. Data from the following instruments were collected.

\section{Demographic Information Form}

An investigator-developed form collected demographic information, including age, gender, nationality, marital status, and educational level.

\section{Professional Characteristics Information Form}

An investigator-developed form collected additional work-related demographics, including the total number of years of nursing experience, title of present position, unit of practice, and a selfevaluation of their perceptions of clinical competency stage [23]. The variables measured on the information surveys were chosen based on a review of the literature that suggested possible relationships between the demographic and professional characteristics that might correlate with compassion fatigue and CS. Content and face validity were established by the group of authors.

\section{Professional Quality of Life: CS and Fatigue Version 5}

The survey instrument used in this study was the compassion satisfaction and Compassion Fatigue (ProQOL) Version 5 instrument [21]. The instrument is a 30 -item self-report tool that measures the experiences associated with helping others and has been in use since 1995. The ProQOL evaluates both the positive and negative effects of caregiving. The positive effects of caregiving are seen as CS, and the negative effects of caregiving are captured as compassion fatigue. Compassion fatigue is subdivided into 2 scales, BO, and the Secondary Traumatic Stress Scale.

Items are evaluated on a 5-point Likert scale (from $1=$ never to $5=$ very often). Total scores for each subscale can be classified as low, moderate, or high. Individual ranges are indicated on each subscale, and scores outside of the range limits may represent a possible risk [24]. Through psychometric testing, the instrument has been shown to demonstrate adequate reliability and validity $[6$, 24]. The ProQOL instrument is the most commonly used tool to measure compassion fatigue in research [9].

\section{Data Collection}

Data were collected using 3 self-administered surveys that were available in a web-based format. Participants could choose to fill out the surveys during regular work hours or complete them outside of work hours. In addition to the email sent on Day \# 5 of the Mass Pilgrim Nursing Assignment, emails were also resent on days $\# 7$, \#10, \#13, and \#15 of the nursing assignment to nonresponding nurses, encouraging them to participate in the study. The study ended on day \#15 of the Mass Pilgrim Working Assignment, and the survey web links were deactivated at the end of day \#15.

\section{Data Analysis}

Survey results were analyzed using SPSS version 21.0 software. The questionnaires were scanned. Descriptive statistics were used to describe the means, standard deviations, and ranges among the variables. Differences in the demographic and professional variables from the subjects of the 2 hospitals were examined using independent sample $t$ tests. Pearson's $r$ was used to investigate correlations between demographic, professional variables, and ProQOL subscales. Questionnaires at least 75\% completed were included in the statistical analysis, with 57 subjects removed before the statistical analysis. All missing data were substituted with the mean score.

\section{Results}

\section{Sample Characteristics}

The total eligible nurses to participate in the study from the 2 hospitals numbered 741 nurses. As 542 nurses completed the surveys, the total response rate was $73.1 \%$. Demographic and professional characteristics were similar between the nurses in the 2 hospitals. The mean age of 
Table 1. Participant's demographic and professional characteristics

\begin{tabular}{|c|c|c|}
\hline \multicolumn{3}{|c|}{ Demographic and professional characteristics, $N=542$} \\
\hline \multicolumn{3}{|l|}{ Age, years } \\
\hline Mean (SD) & $32.1(5.3)$ & \\
\hline Range & $24-58$ & \\
\hline Gender & $n=542$ & $\%$ \\
\hline Female & 392 & 72.3 \\
\hline Male & 150 & 27.7 \\
\hline \multicolumn{3}{|l|}{ Nationality } \\
\hline Philippine & 197 & 36.3 \\
\hline India & 143 & 26.4 \\
\hline Malaysia & 51 & 9.4 \\
\hline Jordan & 49 & 9.0 \\
\hline Saudi Arabia & 47 & 8.7 \\
\hline Egypt & 30 & 5.5 \\
\hline Pakistan & 21 & 3.9 \\
\hline Other & 4 & 0.7 \\
\hline \multicolumn{3}{|l|}{ Marital status } \\
\hline Single & 162 & 29.9 \\
\hline Married & 372 & 68.6 \\
\hline Divorced & 6 & 1.1 \\
\hline Widowed & 2 & 0.4 \\
\hline \multicolumn{3}{|l|}{ Education } \\
\hline Associate degree/diploma & 113 & 20.9 \\
\hline $\mathrm{BSN}$ & 386 & 71.2 \\
\hline Post-BSN diploma & 14 & 2.6 \\
\hline MSN & 29 & 5.4 \\
\hline \multicolumn{3}{|l|}{ Ward/unit } \\
\hline Medical/surgical & 100 & 18.5 \\
\hline Critical care* & 179 & 33.1 \\
\hline Cardiac center** & 64 & 11.8 \\
\hline Oncology center & 38 & 7.0 \\
\hline Neurology & 20 & 3.7 \\
\hline Gynecology/L and D & 27 & 5.0 \\
\hline OPD & 27 & 5.0 \\
\hline Pediatric & 18 & 3.3 \\
\hline Other & 68 & 12.6 \\
\hline \multicolumn{3}{|l|}{ Title of presentation } \\
\hline RN 3 & 81 & 15.2 \\
\hline RN 2 & 179 & 33.6 \\
\hline RN1 & 202 & 38.0 \\
\hline Charge nurse & 33 & 6.2 \\
\hline Head nurse & 27 & 5.1 \\
\hline Nurse manager & 10 & 1.9 \\
\hline \multicolumn{3}{|c|}{ Length of nursing experience, years } \\
\hline Mean (SD) & $9.3(5.1)$ & \\
\hline Range & $0-38$ & \\
\hline
\end{tabular}

OPD, outpatient department; $\mathrm{L}$ and $\mathrm{D}$, labor and delivery. * Critical Care Units: ICUs, ER, OR. ${ }^{* *}$ Cardiac Center: CCU, surgical, CCU, Catheterization Laboratory.

the participants was 32.1 years $(\mathrm{SD}=5.3$, range $=24-58)$. The majority $(72.3 \%)$ of the subjects were female $(n=$ $392)$, married $(n=372,68.6 \%)$ and held a bachelor's degree in nursing $(n=386,71.2 \%)$. No statistically signifi-
Table 2. Participants' self-evaluation of their stage of clinical competence (Benner [23]) $(N=538)$

\begin{tabular}{lrc}
\hline Stages of clinical competency & $N$ & Percent (\%) \\
\hline Novice & 6 & 1.1 \\
Advanced beginner & 37 & 6.9 \\
Competent & 140 & 26.0 \\
Proficient & 191 & 35.5 \\
Expert & 164 & 30.5 \\
\hline
\end{tabular}

cant differences were found between the subjects from the 2 different hospitals. Demographic and professional characteristics of the sample are depicted in Table 1.

The subjects' mean of total nursing experience was 9.3 years $(\mathrm{SD}=5.1$, range $0-38)$. The highest percentage $(n=$ $202,38.0 \%)$ of the subjects were Registered Nurse I (RN1), working in critical care units $(n=179,33.1 \%)$, and classified their Benner's stage of nursing development as proficient ( $n=191,35.5 \%)$. Table 2 illustrates the sample's self-evaluation of their stage of nursing development [23].

\section{Compassion Fatigue and CS (ProQOL)}

Descriptive statistics of the sample yielded a moderate to a high level of compassion fatigue comprised of a (1) moderate to a high level of $\mathrm{BO}(M=22.5, \mathrm{SD}=5.7)$ and a (2) moderate level of secondary traumatic stress $(M=$ $25.0, \mathrm{SD}=6.4$ ). Subjects also reported a higher level of CS $(M=40.5, \mathrm{SD}=6.0)$. Table 3 illustrates the descriptive statistics of compassion fatigue (BO and secondary traumatic stress) and CS of the sample.

The majority of subjects reported a moderate to a high level of compassion fatigue. Almost $73 \%$ of the subjects reported a moderate to a high level of $\mathrm{BO}$, and $76.7 \%$ reported a moderate to a high level of secondary traumatic stress. Only $27.8 \%$ of the sample reported a high level of CS.

\section{The Mass Pilgrim Working Assignment and Compassion Fatigue/Satisfaction}

Correlations among the 3 subscales of ProQOL were calculated in order to investigate relationships between the positive aspects of work (CS) and the negative aspects (compassion fatigue as measured by $\mathrm{BO}+$ secondary traumatic stress) for the full study sample. The results were

- Negative correlation between CS and BO $(r=-0.788$, $p<0.001)$.

- Negative correlation between CS and secondary traumatic stress $(r=-0.320, p<0.001)$.
Saleh/Jenkins/Saleh/Saleh/Abu Sammour/ Tiking/Abujoudeh 
Table 3. Compassion fatigue and CS $(N=542)$

\begin{tabular}{|c|c|c|c|}
\hline Professional quality of life & Subscales & Mean score and range & Interpretation \\
\hline \multirow{6}{*}{$\begin{array}{l}\text { Compassion fatigue } \\
\text { Mean (SD) } \\
\text { Range }\end{array}$} & $\mathrm{BO}$ & $22.5(5.7)$ & \multirow[t]{3}{*}{ Moderate to low } \\
\hline & Mean (SD) & \multirow[t]{2}{*}{$10-46$} & \\
\hline & Range & & \\
\hline & STS & $25.0(6.4)$ & \multirow[t]{3}{*}{ Moderate to low } \\
\hline & Mean (SD) & \multirow{2}{*}{$(10-46)$} & \\
\hline & Range & & \\
\hline CS & & \multirow[t]{3}{*}{$40.56(6)$} & \multirow[t]{3}{*}{ Moderate to high } \\
\hline Mean (SD) & & & \\
\hline Range & & & \\
\hline
\end{tabular}

BO, burnout; CS, compassion satisfaction; STS, secondary traumatic stress.

- Positive correlation between secondary traumatic stress and BO $(r=0.580, p<0.001)$.

A Pearson correlation coefficient was conducted to assess the relationship between the number of the working day of the Mass Pilgrim Nursing Assignment and compassion fatigue and CS. Data were collected on Day \#5 of the assignment through the last day of the assignment on Day \#15. There was a significant positive relationship between the increasing number of working days of the Mass Pilgrim Nursing Assignment and compassion fatigue, comprised of $\mathrm{BO}(r=0.16, N=542, p<0.01)$, and the secondary trauma stress $(r=0.90, N=542, p<0.05)$. There was a significant negative relationship between the number of the working days of the Mass Pilgrim Nursing Assignment and Compassion Satisfaction scores $(r=$ $-0.20, N=542, p<0.01)$. Table 4 illustrates the relationship between the ProQOL subscales and the time (day) the data were submitted.

\section{Correlates of Compassion Fatigue/Satisfaction}

Demographic Correlates

Several significant associations were found between demographic and professional variables and the ProQOL subscales. A Pearson correlation test was conducted to assess the relationship between the age of the study's subjects and the ProQOL subscales. There was a negative relationship between the age of the study's subjects and the level of BO $(r=-0.16, N=543, p<0.001)$. There was positive relationship between the subject's age and CS $(r=0.14, N=543, p<0.001)$.

Gender was associated with secondary traumatic stress. Male were at higher risk of secondary traumatic stress than females $(\mathrm{X} 2[1, N=544]=5.7, p=0.017)$. Ed-
Table 4. Correlation of number of days (Day \#5-Day \# 15) of the Mass Pilgrim Nursing Assignment and ProQOL Subscale Scores $(N=542)$

\begin{tabular}{ll}
\hline & Total \\
\hline CS & $-0.2^{*}$ \\
BO & $0.16^{* *}$ \\
ST & $0.9^{*}$ \\
\hline
\end{tabular}

BO, burnout; CS, compassion satisfaction; STS, secondary traumatic stress. ${ }^{*}<0.05 . * *<0.01$.

ucation was associated with compassion fatigue ( $\mathrm{BO}$ and secondary traumatic stress). Higher levels of education (master degree and post-BSN diploma) were most likely to experience lower level of $\mathrm{BO}(\mathrm{X} 2[2, N=542]=11.33$, $p=0.01)$ and lower level of secondary traumatic stress (X2 $[2, N=542]=9.51, p=0.023)$ than Associate degree, diploma, or BSN nurses.

Egyptians, Filipinos, and Jordanians were more likely to score higher levels of CS than Malaysians, Indians, Saudis, and other nationalities (X2 $[6, N=544]=14.08, p=$ $0.029)$. Saudis, Egyptians, and Jordanians were more likely to experience higher levels of BO than Indians, Filipino, Malaysians, and other nationalities (X2 [6, N = 544] = $29.43, p<0.00$ ).

\section{Professional Correlates}

The title of the present position was associated with different levels of CS levels of BO. Nurses with managerial positions were more likely to experience higher levels of CS $(\mathrm{X} 2[7, N=534]=17.92, p=0.012)$ and lower levels 
of $\mathrm{BO}$ than bedside nurses $(\mathrm{X} 2[2, N=534]=29.36, p=$ $0.00)$.

The association between length in years of nursing experience and the ProQOL subscales was examined. There was a negative relationship between the length of nursing experience and compassion fatigue: (1) BO $(r=-0.169$, $N=544, p<0.01)$ and $(2)$ secondary trauma stress $(r=$ $-0.26, N=544, p<0.01$ ).

Level of perceived clinical competence (Novice-Expert) was associated with levels of CS (X2 [4, N=540] = $12.70, p=0.013)$ and with level of $\mathrm{BO}(\mathrm{X} 2[4, N=540]=$ $10.48, p=0.033)$. The findings suggest that novice and advanced beginner nurses are more likely to experience lower levels of CS and higher levels of BO than competent, proficient, and expert nurses.

\section{Discussion}

This study contributes to the existing knowledge of compassion fatigue by describing compassion fatigue in a large multinational nursing sample from different units, different ranks and positions, and different levels of clinical competence. With an understanding of the negative consequences of compassion fatigue on patients, nurses, and organizations, this study was to examine the effect of Mass Pilgrim Nursing Assignment (15 consecutive working days with 12-h shift) on the participating nurses' levels of compassion fatigue, along with CS; the relationship of compassion fatigue with demographic and professional nurses' characteristics was also examined.

According to the ProQOL scoring instructions [24], scores falling between 23-41 on compassion fatigue (BO and secondary traumatic stress) and CS are considered average. The mean scores of compassion fatigue and CS in this study were found to be at a moderate level. This finding is consistent with other research studies [25-28]. Further analysis indicated $73-76 \%$ of the nurses are at a moderate to a high risk of compassion fatigue, while only $27.8 \%$ of the nurses are at a high level of CS. In the literature, various research findings reported nurses to have a moderate to a high level of compassion fatigue $[29,30]$. Additionally, several studies suggest that nurses, especially critical care nurses, are at high risk of compassion fatigue $[25,30]$. This finding is not surprising since compassion fatigue would be expected to be high as the Mass Pilgrim Nursing Assignment is a very long (15 days/12-h shifts) assignment with no days off.

Although we expected the mean of the compassion fatigue to be at a high level, our explanation for the study's sample scoring at the average level of compassion fatigue consists of 2 parts. First, all nursing units are doublestaffed, and the patient-nurse ratio is at its minimal level in case of any emergency during the special assignment period. Second, this study included nurses from all different units such as critical care (ER, OR, ICU, etc.) areas as well as outpatient departments, labor and delivery (L and D), and pediatrics. During the Mass Pilgrim working assignment, nurses in the critical care units would be at a high alert status and very busy with the increased incoming cases, while nurses working in teams, such as in outpatient department, $\mathrm{L}$ and $\mathrm{D}$, and pediatrics, would be at a less acute level of operation. Therefore, nurses in critical care areas would be experiencing higher levels of compassion fatigue, while pediatric and $\mathrm{L}$ and $\mathrm{D}$ nurses may be experiencing lower levels of compassion fatigue. For example, $86 \%$ of nurses at the cardiac center reported moderate to high levels of $\mathrm{BO}$, whereas only $14.2 \%$ of neonatal nurses reported moderate to high levels of BO. This combination of different specialty nurses appears to have balanced the levels of compassion fatigue at a moderate level.

Compassion fatigue can lead to high frustration, disengagement, and job dissatisfaction, which may lead to workplace incivility and violence, an overall unhealthy work environment [31], jeopardizing the quality of nursing care and the safety of patients. Yang and Kim [19] confirmed that nurses' clinical reasoning and judgment could be impacted by mental stress and compassion fatigue, leading to unsafe delivery of patient care. Therefore, a reconsideration of the Mass Pilgrim Nursing Assignment is warranted. Consideration of alternative scheduling plans during this time may protect the compassionate health of nurses, as well as ensure the delivery of safe and effective quality of nursing care.

The findings of this study indicated that there is a positive relationship between the number of days of the Mass Pilgrim Nursing Assignment and compassion fatigue (BO and secondary traumatic stress) and a negative relationship with CS. As nurses move forward with the 15day Mass Pilgrim Nursing Assignment, there were increasing indications of compassion fatigue, simply due to increased physical and psychosocial burdens. Wu et al. [6] reported that nurses who work more than $36 \mathrm{~h} /$ week experienced higher levels of compassion fatigue. During this 15-day assignment, nurses worked $12 \mathrm{~h}$ and slept 6 to $8 \mathrm{~h}$. They had little time (3-4 h/day) to meet familial and social obligations and for leisure activities, compounding the feelings associated with compassion fatigue. Higher levels of compassion fatigue and emotional exhaustion
Saleh/Jenkins/Saleh/Saleh/Abu Sammour/ Tiking/Abujoudeh 
can lead to poor judgment, loss of empathy, and decreased productivity, often risking patients' safety [28, 32]. In comparison, CS increased as nurses moved forward with the 15-day assignment as they experienced a heightened sense of achievement and success. Also, nurses' CS may be high as they will receive special recognition from the administration, along with a substantial financial incentive after the end of the assignment. The appreciation certificate that nurses receive during the official end-of-assignment general staff meeting serves as one mechanism for providing recognition. This recognition is rewarding as stories are shared on how their work impacted others and made a difference [30].

Older nurses reported lower levels of $\mathrm{BO}$ and higher levels of CS. This finding aligns with the results of previous studies [25, 33-35]. Wu et al. [6] reported that nurses aged 40 years or younger were found to be at higher risk of compassion fatigue. Kelly and Lefton [30] suggested that millennial nurses - or younger generation nurses have the highest level of compassion fatigue. These findings suggest that younger nurses may not experience a sufficient transition from the student role to the staff nurse, have not yet developed critical adaptive behaviors, and lack of collegial support and resources [6].

The findings of this study suggested that male nurses present a higher score of secondary traumatic stress than female nurses, which contradicts the findings of Borges et al. [25], showing female nurses had higher scores of secondary traumatic stress than male nurses. While Al Barmawi et al. [32] reported that female nurses experienced higher levels of CS than male nurses. Mooney et al. [36] presented contradictory findings. Hooper et al. [29] found no relationship between gender and compassion fatigue and CS. More studies with an increased sample size are warranted to resolve these conflicting findings of the relationship between gender and compassion fatigue and CS.

In this study, nurses with a higher level of education (post-BSN education) were most likely to experience compassion fatigue compared with nurses holding an Associate Degree, Diploma, and BSN, while Dikman et al. [12] reported that nurses with Associate Degrees had a higher risk of compassion fatigue than other educated groups. Wu et al. [6] also reported that more educated nurses were found to experience higher levels of CS. One explanation for this finding is that increasing education results in nurses with a broader knowledge base and higher levels of clinical expertise, resources making them more equipped to handle stressful situations and workplace traumas.

Nurses Compassion Fatigue
The study also revealed that the different nationalities of the sample differed in relation to compassion fatigue and CS. The findings of this study suggested that Egyptian, Filipino, and Jordanian nurses score higher levels of CS than Malaysian, Indian, Saudi, and other nationality nurses. Also, Saudi, Egyptians, and Jordanian nurses experienced higher levels of BO than did Indians, Filipino, Malaysian, and other nationality nurses. From a variety of countries and cultures, the sample may experience compassion fatigue and CS differently. There are multiple explanatory theories of why different nurses from different countries - working for the same hospitals - experience such different levels of compassion fatigue and CS. Age, length of nursing experience, competency level, leadership styles, support groups, religion, and culture are different variables that may be influencing nurses' compassion fatigue and CS. Another explanation is that nationalities who develop social supports within and outside the workplace may experience higher CS and lower compassion fatigue. Liu and Aungsuroch [37] suggest that the social support system within the work environments is an essential factor influencing nurses' ability to accommodate the stressful nature of the work settings.

All subjects of this study are Muslim nurses caring for Muslim patients during the performance of the fifth pillar of Islamic religion. This could have increased nurses' CS and reduce nurses' compassion fatigue because nurses are looking for not only financial incentive for this working assignment but also hereafter rewards as stated in Quran and Hadith.

Nurses with managerial positions are more likely to experience higher levels of CS and a lower risk of $\mathrm{BO}$ than bedside nurses. Bedside nurses are exposed to a work experience that places them at a higher than average risk of compassion fatigue development $[28,35,38]$. The bedside nurse's role is filled with stressors such as physical labor, human suffering, overseeing the clinical management of patients, engagement with family members, staffing, and interpersonal relationships that are central to the work nurses do. Also contributing to the increase in nurses' work stress may be related to the increasing use of technology, along with turbulence within the work environment $[39,40]$. All of these factors contribute to the increased level of compassion fatigue of bedside nurses compared with those in managerial positions who are dealing with different types of stressors: health-care cost issues, unit budgeting, quality of care, unit staffing, and workers' problems.

There was a negative relationship between the length of nursing experience and compassion fatigue. The in-

Saudi J Health Syst Res 2021;1:41-50

DOI: $10.1159 / 000514644$ 
creasing length of experience resulted in a lower risk of compassion fatigue. These findings parallel previous studies $[6,12,25,38]$. Another related finding suggests that novice and advanced beginner nurses are more likely to experience lower levels of CS and a higher risk of BO than competent, proficient, and expert nurses. These findings may suggest that experienced nurses may develop needed professional resiliency skills $[38,41]$ and gain the wisdom and the skills to be maximally functional with the workplace stressors over time.

\section{Implications}

Throughout the discussion of the results of this study, evidence has emerged that it is essential for health-care organizations to provide a healthy, supportive, and positive working environment to ensure nurses' well-being. Health-care organizations must actively demonstrate the value and appreciation of nursing staff through recognizing, acknowledging, and celebrating extraordinary work. Organizations must create preventive interventions and provide psychosocial counseling for nurses experiencing compassion fatigue and other personal issues. Providing spiritual resources is another preventive intervention that can mitigate compassion fatigue [22]. An additional intervention toward a successful intervention and resolution of compassion fatigue is education. Educational programs may include enhancing overall communication strengths, improving team collaboration and relationship skills, adding training in stress management, conflict management, cultural competency, diversity management, emotional intelligence, customer service, leadership development, or other programs that could enhance organizational proficiency [42]. Finally, health-care organizations need to have clear policies and guidelines on the maximum hours worked by nurses.

Nurse managers can help staff nurses to avoid reaching compassion fatigue levels. First, provide consistent, compassionate, and culturally sensitive leadership support. Evidence suggests that support from leaders and colleagues may decrease compassion fatigue and increase job satisfaction among the nurses [43]. Second, establish unit support groups with regular outside workplace gatherings for leisure activities, especially for younger nurses, so that they can meet and talk about their concerns. Third, promote unit stability by introducing teamwork and team-building activities to boost confidence and enhance shared governance decision-making. Fourth, staff assignments should not exceed 36 working hours/per week. Rotation of nurses through overtime is essential instead of having a few nurses carrying all the unit's overtime, lead- ing to compassion fatigue. Fifth, establishing a Mentor Link Program, where novice nurses are assigned to experienced, proficient nurses as a resource person. This program will create an opportunity for younger and less experienced nurses to verbalize concerns and find support when needed. Sixth, promoting team debriefing activities after traumatic, stressful, or unusual events [38]. Seventh, mixing novice and advanced beginner nurses with competent, proficient, and expert nurses in each shift is a must. This will help in transitioning nurses from novice to a competent level. Finally, Upton [44] suggests that managers need to adopt behaviors that give their staff the permission and the opportunity to develop an appropriate level of self-compassion.

Nurses can help themselves in mitigating compassion fatigue. First, nurses should be aware of causes, symptoms, and behaviors of compassionate fatigue, so they can find ways and develop strategies to help themselves and colleagues through the episodes of compassion fatigue. Second, nurses need to learn self-compassion - allowing oneself to be the object of care and concern. Self-compassion has been shown to contribute to well-being, alleviating depression and other psychosocial conditions. Third, nurses need to utilize all available educational resources such as educational seminars, workshops, and courses to help learn about and deal with compassion fatigue. Finally, nurses need to be aware that the American Nurses Association Code of ethics identifies that it is the responsibility of nurses to ensure work-life balance by including health behaviors to decrease the impact of compassion fatigue [45].

In 2013, the American Nurses Association (ANA) [46] addressed compassion fatigue in relation to nurses and employers. First, RNs are responsible for considering their level of fatigue when deciding to take on assignments beyond their regularly scheduled workday or week. Second, the employer needs to promote healthy nurse work hours in all roles and settings. Additionally, the Joint Commission [47] encourages health-care facilities to assess their policies to avoid fatigue-related risks, such as consecutive shift work that may be contributing to nursing fatigue.

\section{Limitations}

In this study, several limitations were identified. Although the results of this study provided a view of compassion fatigue experienced in a particular setting, the design of this study does not extrapolate the study's findings to other contexts.

As with all surveys, self-selection to participate can be a possible confounding variable. Nurses who participated
Saleh/Jenkins/Saleh/Saleh/Abu Sammour/ Tiking/Abujoudeh 
in this study may have high satisfaction levels, may have been recognized by the administration, or may not have experienced any recent stressors. Nonparticipating nurses may be experiencing dissatisfaction with the workplace, resulting in disengagement.

The ProQOL instrument may not be sensitive enough to accurately measure compassion fatigue in nurses because the cutoff scores of BO, secondary traumatic stress, and CS are based on the data obtained from all professionals and, thus, were not limited to nurses. Several studies suggested that the ProQOL instrument may not be sensitive to the nature of the nurses' work $[28,38]$.

The subjects of this study represented different cultures and were mainly from the Far East and the Middle Eastern countries. Therefore, one generic instrument, such as the ProQOL, may not have captured the different cultural experiences of compassion fatigue. Thus, the use of a more culturally sensitive instrument might capture the compassion fatigue experience more accurately.

This study included nurses from all units and all positions. We could have obtained more accurate data on compassion fatigue if we have restricted the inclusion criteria. For example, we should not have mixed bedside nurses with managerial nurses. As well, we should not have mixed critical care units with other units such as pediatric and L and D units. Finally, this study was carried out in only 2 hospitals located in the Western Province of Saudi Arabia, thus limiting the generalizability of the findings.

\section{Conclusion}

The study revealed the presence of moderate compassion fatigue and CS during a lengthy special work assignment. Results demonstrated that compassion fatigue is related to age, gender, education, nationalities, length of nursing experience, and competency levels. Further research on the compassion fatigue phenomenon could support the development of health promotion and selfcompassion strategies in the workplace. Future research needs to be directed toward younger generations of nurses since they are more susceptible to compassion fatigue. These studies need to explore and evaluate strategies to alleviate compassion fatigue and consequently retain the younger generation in the profession. Further research directed to examine the efficacy of prevention strategies and interventions to mitigate compassion fatigue at the nurse level, the unit level, and the organization level is warranted. Additionally, more studies are warranted to develop, refine, and examine the nursing-specific compassion fatigue experience, considering the religious and cultural sensitivity of the data collection instruments.

\section{Statement of Ethics}

Permission to conduct the study was granted by the Institutional Review Board of each hospital. Study approval reference numbers as following, King Abdullah Medical City IRB number 18-425 and Security Forces Hospital - Makkah IRB number 0215140818. The purpose of this study was provided along with an explanation of confidentiality and data anonymity procedures. A personalized email message was then sent to all eligible subjects; the email described human subjects' rights and indicated that consent to participate would be determined by clicking on the informed consent link. Subjects needed to click on "agree" after reading the informed consent to be able to access the study's surveys.

\section{Conflict of Interest Statement}

We have no conflicts of interest to disclose.

\section{Funding Sources}

This research received no specific grant from any funding agency in the public, commercial, or not-for-profit sectors.

\section{Author Contributions}

In addition to the Principal Investigator, 6 other researchers assisted in data collections, analysis, and manuscript preparation. All the authors of this manuscript have contributed to this original research manuscript.

References

1 Puri-Mirza A. Number of Hajj pilgrims in Saudi Arabia 1999-2019. Statistica. 2020 Aug 26. Available from: https://www.statista.com/ statistics/617696/saudi-arabia-total-hajj-pilgrims/

2 Ridda I, Mansoor S, Briggs R, Gishe J, Aatmn D. Preparedness for mass gathering during Hajj and Umrah. Handbook of healthcare in the Arab World. 2019 May 1-21.

3 Perry B. Conveying compassion through attention to the essential ordinary. Nurs Older People. 2009;21(6): 14-22.

4 Singh P, King-Shier K, Sinclair S. The colours and contours of compassion: a systematic review of the perspectives of compassion among ethnically diverse patients and healthcare providers. PLoS One. 2018;13(5):e0197261. 
5 Bramley L, Matiti M. How does it really feel to be in my shoes? Patients' experiences of compassion within nursing care and their perceptions of developing compassionate nurses. J Clin Nurs. 2014;23(19-20):2790-9.

6 Wu S, Singh-Carlson S, Odell A, Reynolds G, $\mathrm{Su}$ Y. Compassion fatigue, burnout, and compassion satisfaction among oncology nurses in the United States and Canada. Oncol Nurs Forum. 2016;43(4):E161-E169.

7 Figley CR, editor. Epilogue: the transmission of trauma. In: Compassion fatigue: coping with secondary traumatic stress disorder in those who treat the traumatized. Oxfordshire: Routledge Taylor \& Francis Group; 1995. p. 249-54.

8 Van Mol MM, Kompanje EJ, Benoit DD, Bakker J, Nijkamp MD. The prevalence of compassion fatigue and burnout among healthcare professionals in intensive care units: a systematic review. PLoS One. 2015;10(8): e0136955.

9 Sinclair S, Raffin-Bouchal S, Venturato L, Mijovic-Kondejewski J, Smith-MacDonald L. Compassion fatigue: a meta-narrative review of the health care. Int J Nurs Stud. 2017;69: 9-24.

10 MedEd Web Solutions. State of well-being. A comprehensive report on the state of well-being among heathcare workers in 2019. Wellbeing [Internet]. 2019. Available from: https: //www.mededwebs.com/well-being-index.

11 Sorenson C, Bolick B, Wright K, Hamilton R. Understanding compassion fatigue in healthcare providers: a review of current literature. J Nurs Scholarsh. 2016;48(5):456-65.

12 Dikmen Y, Aydın Y, Tabakoğlu P. Compassion fatigue: a study of critical care nurses in Turkey. J Hum Sci. 2016;13(2):2879-84.

13 Figley CR. Compassion fatigue: psychotherapists' chronic lack of self care. J Clin Psychol. 2002;58(11):1433-41.

14 Cimiotti JP, Aiken LH, Sloane DM, Wu ES. Nurse staffing, burnout, and health care-associated infection. Am J Infect Control. 2012 40(6):486-90.

15 Alharbi J, Jackson D, Usher K. Compassion fatigue in critical care nurses and its impact on nurse-sensitive indicators in Saudi Arabian hospitals. Aust Crit Care. In press.

16 Sun YY, Zhao H, Ni CX. The relationship between nursing work errors and job satisfaction, job burnout: empirical study on some tertiary hospitals. Chin J Health Policy. 2018; 11(4):69-72.

17 Welp A, Meier LL, Manser T. Emotional exhaustion and workload predict clinician-rated and objective patient safety. Front Psychol. 2015;5:1573.

18 Wells-English D, Giese J, Price J. Compassion fatigue and satisfaction: Influence on turnover among oncology nurses at an urban cancer center. Clin J Oncol Nurs. 2019;23(5): 487-93.
19 Yang YH, Kim JK. Factors influencing turnover intention in clinical nurses: Compassion fatigue, coping, social support, and job satisfaction. J Korean Acad Nurs Adm. 2016; 22(5):562-9.

20 Smart D, English A, James J, Wilson M. Compassion fatigue and satisfaction: A cross-sectional survey among US healthcare workers. Nurs Health Sci. 2014;16(1):3-10.

21 Stamm BH. Helping the helpers: compassion satisfaction and compassion fatigue in selfcare, management, and policy of suicide prevention hotlines. In: Kirkwood AD, Stamm $\mathrm{BH}$, editors. Resources for community suicide prevention [CD]. Idaho: Idaho State University; 2012

22 Yılmaz G, Üstün B. Professional quality of life in nurses: compassion satisfaction and compassion fatigue. J Psychiatr Ment Health Nurs. 2018;9(3):205-11.

23 Benner P. From novice to expert: Excellence and power in clinical nursing power. Boston: Addison-Wesley; 1984.

24 Stamm BH. The concise ProQOL manual. 2nd ed. ProQOL.org. 2010. Available from: https: //proqol.org/uploads/ProQOLManual. pdf.

25 Borges EMDN, Fonseca CINDS, Baptista PCP, Queirós CML, Baldonedo-Mosteiro M, Mosteiro-Diaz MP. Compassion fatigue among nurses working on an adult emergency and urgent care unit. Rev Lat Am Enfermagem. 2019;27:e3175.

26 Duarte J. Professional quality of life in nurses: contribution for the validation of the Portuguese version of the Professional Quality Of Life Scale-5 (ProQOL-5). Análise Psicológica. 2017;35(4):529-42.

27 Hunsaker S, Chen HC, Maughan D, Heaston $S$. Factors that influence the development of compassion fatigue, burnout, and compassion satisfaction in emergency department nurses. J Nurs Scholarsh. 2015;47(2):186-94.

28 Kelly L, Runge J, Spencer C. Predictors of compassion fatigue and compassion satisfaction in acute care nurses. J Nurs Scholarsh. 2015;47(6):522-8.

29 Hooper C, Craig J, Janvrin DR, Wetsel MA, Reimels E. Compassion satisfaction, burnout, and compassion fatigue among emergency nurses compared with nurses in other selected inpatient specialties. J Emerg Nurs. 2010; 36(5):420-7.

30 Kelly LA, Lefton C. Effect of meaningful recognition on critical care nurses' compassion fatigue. Am J Crit Care. 2017;26(6):438-44.

31 Fernandez-Parsons R, Rodriguez L, Goyal D. Moral distress in emergency nurses. J Emerg Nurs. 2013;39(6):547-52.

32 Al Barmawi MA, Subih M, Salameh O, Sayyah Yousef Sayyah N, Shoqirat N, Abdel-Azeez Eid Abu Jebbeh R. Coping strategies as moderating factors to compassion fatigue among critical care nurses. Brain Behav. 2019;9(4): e01264.
33 Grafton E, Gillespie B, Henderson S. Resilience: the power within. Oncol Nurs Forum. 2010;37(6):698-705.

34 Perry B, Toffner G, Merrick T, Dalton J. An exploration of the experience of compassion fatigue in clinical oncology nurses. Can Oncol Nurs J. 2011;21(2):91-105.

35 Sacco TL, Ciurzynski SM, Harvey ME, Ingersoll GL. Compassion satisfaction and compassion fatigue among critical care nurses. Crit Care Nurse. 2015;35(4):32-43.

36 Mooney C, Fetter K, Gross BW, Rinehart C, Lynch C, Rogers FB. A preliminary analysis of compassion satisfaction and compassion fatigue with considerations for nursing unit specialization and demographic factors. J Trauma Nurs. 2017;24(3):158-63.

37 Liu Y, Aungsuroch Y. Work stress, perceived social support, self-efficacy and burnout among Chinese registered nurses. J. Nurs. Manag.. 2019;27(7):1445-53.

38 Al-Majid S, Carlson N, Kiyohara M, Faith M Rakovski C. Assessing the degree of compassion satisfaction and compassion fatigue among critical care, oncology, and charge nurses. J Nurs Adm. 2018;48(6):310-5.

39 Browne J, Braden CJ. Nursing turbulence in critical care: Relationships with nursing workload and patient safety. Am J Crit Care. 2020;29(3):182-91.

40 Chang CP, Lee TT, Liu CH, Mills ME. Nurses' experiences of an initial and reimplemented electronic health record use. Comput Inform Nurs. 2016;34(4):183-90.

41 Kolthof KL, Hickman SE. Compassion fatigue among nurses working with older adults. Geriatr Nurs. 2017;38(2):106-9.

42 Rosenstein AH. Hospital administration response to physician stress and burnout. Hosp Pract. 2019;47(5):217-20.

$43 \mathrm{Yu} \mathrm{H}$, Jiang A, Shen J. Prevalence and predictors of compassion fatigue, burnout and compassion satisfaction among oncology nurses: a cross-sectional survey. Int J Nurs Stud. 2016; 57:28-38.

44 Upton KV. An investigation into compassion fatigue and self-compassion in acute medical care hospital nurses: A mixed methods study. J of Compassionate Health Care. 2018;5(1).

45 American Nurses Association. Code of ethics for nurses with interpretive statements. 2015. Available from: https://www.nursingworld. org/practice-policy/nursing-excellence/ethics/code-of-ethics-for-nurses/coe-view-only/.

46 American Nurses Association. ANA 2013 annual report. New beginnings: a year of engagement. 2013. Available from: https:// www.nursingworld.org/ 48db37/globalassets/docs/ana/ana2013annualreport.pdf.

47 The Joint Commission. Sentinel event alert 48: Health care worker fatigue and patient safety. 2018 May. Available from: https:// www.jointcommission.org/resources/patient-safety-topics/sentinel-event/sentinelevent-alert-newsletters. 